\title{
Depressive symptoms in acromegaly: factors that affect their incidence and severity?
}

\author{
Adam Malicki \\ Student of Medical University of Lublin, Poland \\ (iD) https://orcid.org/0000-0003-3555-2190 \\ Joanna Malicka \\ Department of Endocrinology, Medical \\ University of Lublin, Poland \\ (iD) https://orcid.org/0000-0002-7130-9828 \\ Corresponding author: malickajoanna@interia.pl

\section{Emilia Potembska} \\ Department of Psychiatric Nursing, Medical \\ University of Lublin, Poland \\ (iD) https://orcid.org/0000-0001-5244-1594
}

\section{Agnieszka Zwolak}

Chair of Internal Medicine and Department of Internal Medicine in Nursing, Medical University of Lublin, Poland

(iD) https://orcid.org/0000-0002-2556-4705

\section{Dariusz Malicki}

Alcohol Dependence Treatment Ward,

Neuropsychiatric Hospital of Lublin, Poland

Patrycja Rogowska

Student of Medical University of Lublin, Poland

(D) https://orcid.org/0000-0002-8701-299X
DOI: https://doi.org/10.20883/medical.e453

Keywords: depression, acromegaly, Beck Depression Inventory-II, BDI-II

Published: 2020-09-28

How to cite: Malicki A, Malicka J, Potembska E, Zwolak A, Malicki D, Rogowska P. Depressive symptoms in acromegaly: factors that affect their incidence and severity? JMS [Internet]. 2020 Sep 28;89(3):e453. doi:10.20883/medical.e453

(c) 2020 by the author(s). This is an open access article distributed under the terms and conditions of the Creative Commons Attribution (CC BY-NC) licencse. Published by Poznan University of Medical Sciences

\section{ABSTRACT}

Aim. The study aimed to evaluate the influence of acromegaly on the prevalence and the severity of depressive symptoms in patients with active and inactive disease.

Material and Methods. The study group comprised 56 patients with acromegaly, which were divided into two groups based on growth hormone (GH) and insulin-like growth factor (IGF-1) levels, with controlled/cured and with uncontrolled acromegaly. The presence and severity of depressive symptoms were assessed using the Beck Depression Inventory-II (BDI-II).

Results. The mean score of BDI-II in the whole group of patients was $13.43 \pm 10.41$, with no significant difference in the severity of depressive symptoms between patients with cured/controlled and uncontrolled acromegaly $(p=0.620)$. Similarly, the lack of statistically significant differences was confirmed in patients with micro- and macroadenomas, as well as with and without hypopituitarism. There were no significant correlations between BDI-II scores and GH or IGF-1 levels, patient age or duration of the illness.

Conclusions. Depressive symptoms are common in acromegalic patients even if remission has been attained. They are most likely caused by psychological, non-organic causes. Patients diagnosed with acromegaly should undergo a screening BDI test as a part of comprehensive care, and in the event of elevated levels should be provided with a psychiatric consultation and psychological care.

\section{Introduction}

Acromegaly is a rare disease with a prevalence estimated at 4-13 cases per 100,000 population
$[1,2]$, mainly caused by a growth hormone $(\mathrm{GH})$ producing pituitary adenoma. The consequence of the disease is excessive secretion of growth factors, mainly insulin-like growth factor-1 (IGF-1). 
It is a chronic disease that progresses slowly, with symptoms developing gradually, and it usually takes about 5-10 years to determine a proper diagnosis. By this time, a spectrum of physical changes is already distinguishable and can visibly alter one's appearance. The main clinical features are enlarged hands and feet, thickened skin, facial changes including large ears, nose, tongue and lips, prognathism with wide spacing and premature tooth loss, excessive enlargement of superciliary arches and frontal tubers as well as other skeletal deformations (see Figure 1). These features are accompanied by metabolic disturbances, such as hypertension and disorders of carbohydrate metabolism, including diabetes, myocardial dysfunction, breathing disorders, visceromegaly and degenerative changes in the motor system. Acromegaly also significantly increases the risk of developing various tumours, both benign and malignant. Large pituitary adenomas can also cause visual impairment and other neurological disorders [3-5].

Metabolic disturbances, as well as changes in internal organs and appearance, maybe irreversible even after successful treatment. Con- sequently, patients with acromegaly often suffer from a decreased perception of general wellbeing, dissatisfaction with body image and tendency towards social isolation, sexual dysfunction and severe impairment of their quality of life [6-8]. Thus, acromegaly resulting in both physical and psychological limitations can increase the risk of depression and may have a negative impact on patients' quality of life even if they are in remission $[6,9,10]$.

Additionally, it was confirmed that $\mathrm{GH}$ and IGF-I act on the brain through many mechanisms including several neurotransmitter systems, astrocyte intercellular communication, glucose energy metabolism, neuronal dendritic ultrastructure, and cerebral blood flow. IGF-I has a neuroprotective and regenerative role in the central nervous system, as it affects proliferation, cellular differentiation and various plasticity-related processes in several regions of the brain. Moreover, it enhances neurogenesis and increases oligodendrocyte recruitment of newborn cells in the hippocampus. These processes seem to be involved in various aspects of brain functions, such as ageing, undergoing stress, exercising

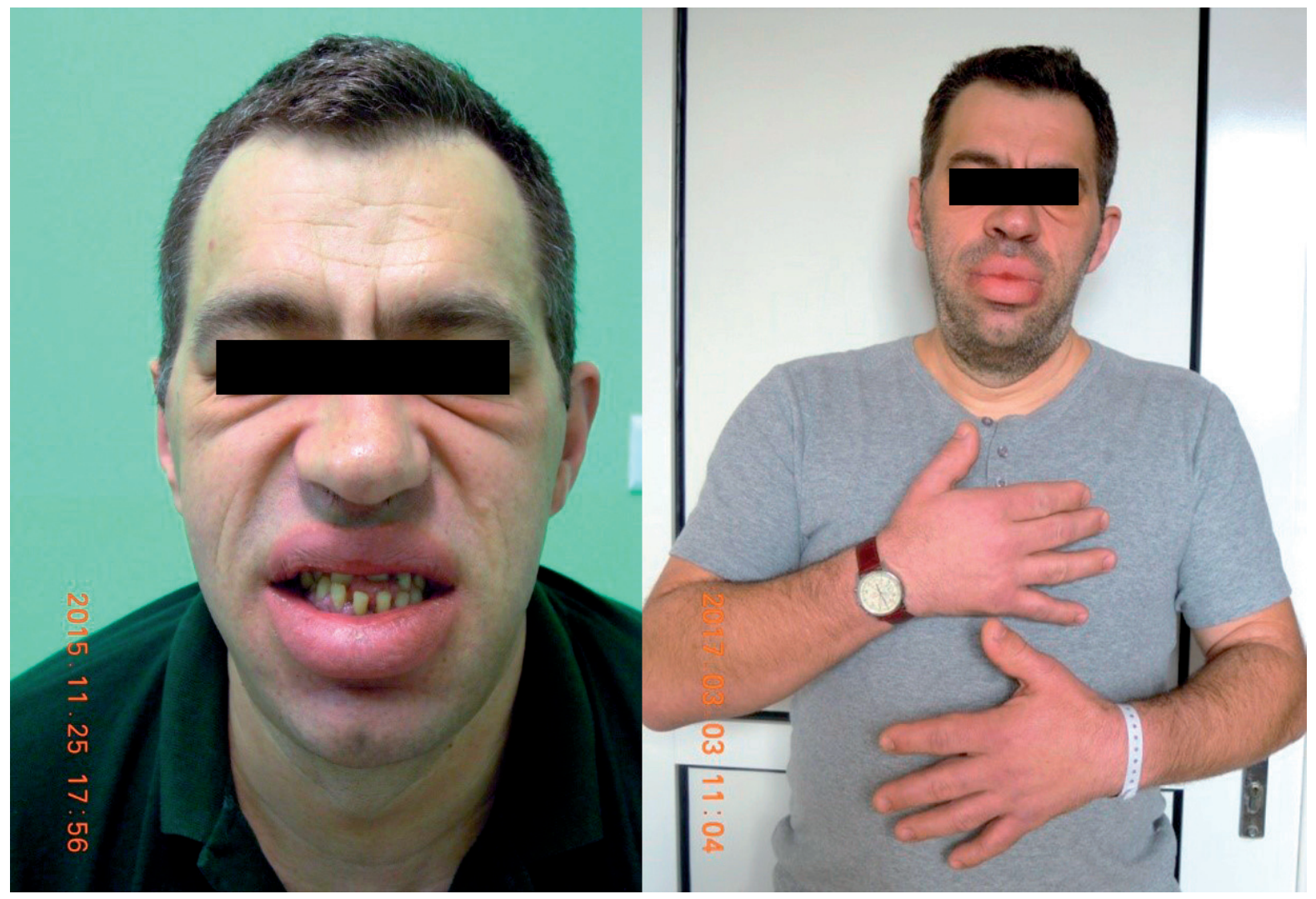

Figure 1. Typical symptoms of acromegaly in a 45 -year-old patient 
and learning [11]. Nonetheless, in a condition of chronic GH/IGF-1 excess, their effects could be paradoxically detrimental. Martin-Rodriquez et al. showed that acromegalic patients presented lower activity in the right dorsolateral prefrontal cortex and left parahippocampal cortex than healthy controls [12].

\section{Aim}

The aim of the study was to evaluate the influence of acromegaly on the prevalence and the severity of depressive symptoms in patients with cured or controlled and uncontrolled disease.

\section{Material and Methods}

The study group comprised 56 patients with acromegaly (37 women, i.e. $66.1 \%$ of the study group and 19 men, i.e. $33.9 \%$ of the study group), aged 25-82 years (mean $57.6 \pm 11.2$ ) hospitalised in the Department of Endocrinology of Medical University in Lublin. Diagnosis of acromegaly was determined by the presence of typical clinical findings, failure to suppress the $\mathrm{GH}$ level to less than $1.0 \mathrm{ng} /$ $\mathrm{ml}$ during an oral glucose tolerance test (OGTT), high levels of IGF-1 adjusted for age and gender, as well as the presence of adenoma in magnetic resonance imaging (MRI) pictures. In one case without visible pituitary adenoma, despite multiple imaging studies, the cause of over-produc- tion of GH was not determined. Disease duration ranged from newly diagnosed to 31 years (mean $8.8 \pm 8.4$ years). The whole group was divided into two subgroups: the first with controlled or cured acromegaly $(\mathrm{n}=27)$ and the second with uncontrolled acromegaly $(n=29)$. The characteristics of the study group are presented in Table 1.

According to Polish recommendations [5], acromegaly was considered cured as a result of surgery when both the circulating IGF-1 level was within the normal age and gender-adjudged range and $\mathrm{GH}$ was less than $1.0 \mathrm{ng} / \mathrm{ml}$ during OGTT. Simultaneously, it was considered controlled during pharmacological treatment when both the circulating IGF-1 level was within the normal age and gender-adjudged ranges and random $\mathrm{GH}$ was less than $1.0 \mathrm{ng} / \mathrm{ml}$ [5].

The presence and severity of depressive symptoms was assessed by the Beck Depression Inventory-II (BDI-II), a self-reported measure of the severity of depressive symptoms over the last two weeks. It has 21 items with a four-point scale ranging from 0 to 3 and the total score is the sum of each item-rating and can range from 0 to 63 . Higher scores indicate greater symptom severity. The BDI-II can be used as a screening tool to detect depression in normal populations or as a tool to assess symptom severity in clinical populations. Depending on the population, there is a different interpretation of the BDI-II scores, for example, according to Smarr and Keefer [13], the following guidelines have been proposed: minimal range $0-13$, mild depression 14-19, moderate depression

Table 1. Subject characteristics

\begin{tabular}{|c|c|c|c|c|}
\hline Variables & $\begin{array}{c}\text { The whole } \\
\text { group } \\
n=56\end{array}$ & $\begin{array}{l}\text { Controlled / } \\
\text { cured } n=27\end{array}$ & $\begin{array}{c}\text { Uncontrolled } \\
n=29\end{array}$ & p \\
\hline Gender (male/female) & $19 / 37$ & $8 / 19$ & $11 / 18$ & - \\
\hline Age (years) mean $\pm S D$ & $57.6 \pm 11.2$ & $60.7 \pm 9.5$ & $54.7 \pm 12.1$ & $p=0.044$ \\
\hline Duration of acromegaly from diagnosis (years) mean $\pm S D$ & $8.8 \pm 8.4$ & $9.7 \pm 6.6$ & $8.0 \pm 9.7$ & $p=0.442$ \\
\hline $\mathrm{GH}(\mathrm{ng} / \mathrm{ml})$ mean $\pm \mathrm{SD}$ & $7.14 \pm 18.1$ & $0.59 \pm 0.58$ & $13.01 \pm 23.59$ & $p=0.010$ \\
\hline IGF-1 $(\mathrm{ng} / \mathrm{ml})$ mean $\pm \mathrm{SD}$ & $333.2 \pm 278.2$ & $151.3 \pm 59.8$ & $502.5 \pm 295.1$ & $\mathrm{p}<0.001$ \\
\hline Microadenoma & 10 & 6 & 4 & - \\
\hline Macroadenoma & 45 & 21 & 24 & - \\
\hline Tumour not visible & 1 & 0 & 1 & - \\
\hline \multicolumn{5}{|l|}{ Treatment of acromegaly } \\
\hline Previous surgery only & 17 & 16 & 1 & \\
\hline Previous surgery + radiotherapy & 2 & 1 & 1 & \\
\hline Previous surgery + medical treatment & 18 & 7 & 11 & \\
\hline Medical treatment only & 17 & 3 & 14 & \\
\hline None & 2 & 0 & 2 & \\
\hline Hypopituitarism (appropriate hormone replacement therapy) & 15 & 7 & 8 & \\
\hline
\end{tabular}


20-28 and severe depression 29-63. In a psychiatric population of the patients diagnosed with depression, a score of $0-13$ is considered minimal depression $[14,15]$ but as "no depressive symptoms" in the non-psychiatric population according to Oleszko et al. [16]. Our group of patients with acromegaly was classified as non-psychiatric.

The results were subjected to statistical analysis using STATISTICA 10.OPL. Two independent groups were compared using the Student's t-test. The $\chi 2$ test was used to compare two independent groups for sociodemographic and nominal variables. An analysis of ANOVA variance with multiple post hoc comparative Tukey's tests were used to compare three independent groups. The correlation between the severity of depressive symptoms and selected clinical variables was analysed using the Pearson correlation test. The significance level of $p<0.05$ indicating the presence of statistically significant differences or dependencies was accepted.

\section{Results}

BDI-II total score in the whole group of the patients ranged from 0 to 35 , with a mean value of $13.43 \pm 10.41$, which corresponds to the bor- derline value for diagnosing mild depression. Thirty-one patients $(55.4 \%)$ scored $0-13$ indicating no depression, while almost half the group (44.6\%) presented scores suggesting potential depressive disorder: 8 (14.3\%) mild depression (scores 14-18), 11 (19.6\%) moderate depression (scores $20-26)$, and 6 (10.7\%) severe depression (scores 29-35), as shown in figure 2. There was no statistically significant difference in the severity of depressive symptoms between patients with cured/controlled disease (mean score = $12.70 \pm 9.27$ ) and uncontrolled acromegaly (mean score $=14.10 \pm 11.49 ; p=0.620$ ). However, there was only one result corresponding to the diagnosis of severe depression in the subgroup with cured/ controlled acromegaly and five cases in the subgroup with uncontrolled disease (Figure 2).

Similarly, the lack of statistically significant differences was confirmed in relation to the severity of depressive symptoms in patients with micro- and macroadenomas $(p=0.559)$ as well as in patients with and without hypopituitarism $(p=0.502)$.

There were no statistically significant correlations between the severity of depressive symptoms and patient age, duration of illness or $\mathrm{GH}$ and IGF1 concentrations.

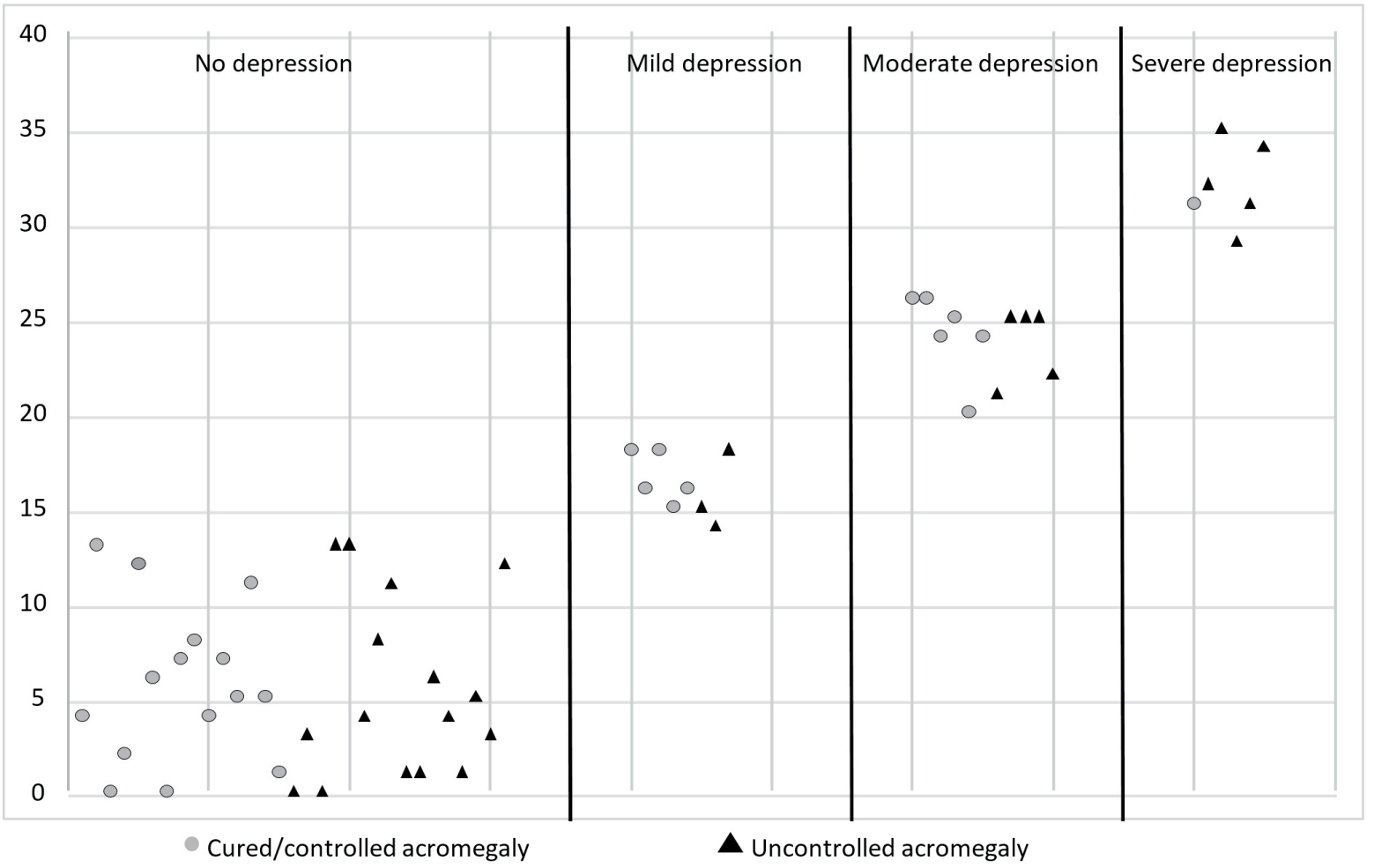

Figure 2. BDI-II scores in both groups of patients 


\section{Discussion}

There are very few reports concerning the psychiatric complications of acromegaly. Manfred Bleuler was probably the first to deal with this problem, describing personality changes characterised by lack of initiative and spontaneity with brief periods of impulsive behaviour and, at times, cheerfulness and self-satisfaction in 1951. He also observed brief mood swings with periods of anxiety along with bradyphrenia, egocentricity and lack of concern [17]. In the 1960s, 1970s and 1980s, there were also few reports concerning the problem of acromegaly and depressive symptoms [18-23]. Today, depression is a very widespread and valid problem as numerous studies have shown an increase in its incidence in the general population.

Depression commonly affects patients with various somatic illnesses, especially hypertension, ischaemic heart disease and diabetes [24] and can be associated with a reduced quality of life and a poorer course and prognosis of their illness [25-29]. Furthermore, a somatic disease can also be responsible for the occurrence of depression and co-occurrence of the mentioned disorders can significantly contribute to a delay in diagnosis, leading to worsening of the clinical course of both diseases [30].

BDI-II sores in the general population differ according to several reports but usually do not exceed several points. For example, in the study conducted on 576 students by Whisman [31], the mean BDI-II total score was $8.36 \pm 7.16$ and a median BDI score of 9 was reported for a cohort of healthy female controls by Celik [7]. In a study of 341 healthy men in Poland by Łopuszańska [32], the mean score of depressive symptoms was $7.8 \pm 5.1$ and positively correlated with age.

In our group of patients, the mean total score of BDI-II was $13.43 \pm 10.41$, which was worse not only in comparison with the general population but also in comparison with other results in patients with acromegaly. For instance, with reference to the study conducted by Crespo [33], the total score of BDI-II in acromegalic patients was 9 (0-27), significantly higher when compared with controls [1 $(0-17), p<0,001]$.

In our group, similar to other studies [6,7], the difference in BDI scores between controlled and uncontrolled patients was not significant. We also confirmed the lack of significant differences in relation to the severity of depressive symptoms in patients with micro- and macroadenomas, as well as in patients with and without hypopituitarism. There were no statistically significant correlations between the severity of depressive symptoms and patient age, duration of illness or $\mathrm{GH}$ and IGF1 concentrations.

To conclude, the occurrence and severity of depressive symptoms do not correlate with disease duration and activity, demographic data, biochemical parameters or the size of the pituitary adenoma, which, according to the authors, can be explained in the terms of psychological causes of depression.

There are few reports in the medical and psychological literature regarding mental and emotional disorders in patients with acromegaly despite their importance in this chronic and debilitating disease. In addition to the signs and symptoms of $\mathrm{GH}$ excess, patients display a loss of initiative and spontaneity, mood swings, self-esteem disturbances, distorted body image, interpersonal relations disorders, and fear of social withdrawal $[34,35]$. In a study of 118 patients with acromegaly, Biermasz et al. proved that joint complaints had contributed to a reduced perception of life quality for these patients. Moreover, patients with a history of myocardial infarction had reduced scores for general health, depression and fatigue, while diabetes mellitus was associated with reduced scores for anxiety and sleep [36]. T'Sjoen et al. confirmed the marked impairment of the patients' quality of life, especially in relation to appearance with a simultaneous lack of correlation regarding biochemical markers of disease activity [8]. Moreover, patients report a chronic impairment of well-being as a consequence of lasting cosmetic and orthopaedic deformities despite normalisation of GH/IGF-I secretion $[34,36]$. Our results also suggest that depressive symptoms are probably associated with the changes that arise in the organism and self-perception of the patient, or with the fear of having a severe chronic disease. It is unlikely that they are related to disease activity or GH and IGF-1 direct effects on the brain.

Currently, an improvement in surgical techniques and pharmacological treatment has made it easier to gain control of acromegaly. However, the assessment of the treatment's efficiency is still based more on hormonal tests and imaging techniques estimating tumour shrinkage and less 
on evaluating the mental health and well-being of the patient, which we suggest is equally important. A similar opinion is shared by other authors who have proved that depression and anxiety seem to have a significant impact on the quality of life in acromegaly, greater than biochemical parameters [37]. Therefore, it is advisable to consider adequate treatment, which, as De Sousa proved with escitalopram and cognitive therapy [38], can bring very beneficial results.

Our study has some limitations. Acromegaly is a relatively rare disease so the study group is small and restricted to data from only one centre. The heterogeneity of the study population and the possible impact of treatment (surgery, radiotherapy, pharmacotherapy, hypopituitarism) should also be considered. Also, the study did not include a control group of healthy people. Nevertheless, the problem seems to be very important and requires further analysis.

\section{Conclusions}

This study shows that regardless of the disease activity, depressive symptoms are common in acromegalic patients. Also, as the occurrence and severity of depressive symptoms do not correlate with the demographic data, the biochemical parameters or the size of the pituitary adeno$\mathrm{ma}$, the authors believe that they may have potential psychological, non-organic causes. They could be associated primarily with the adverse changes that acromegaly causes in the appearance of patients and with the complications of the disease, which emphasises the need for early diagnosis of acromegaly. Furthermore, to optimise the management, dimensions that reflect mental state and quality of life should be evaluated in addition to biochemical and radiological parameters in acromegaly. Patients diagnosed with acromegaly should undergo a screening BDI test as a part of comprehensive care, and in the case of obtaining elevated results, they should be provided with a psychiatric consultation and psychological care.

\section{Acknowledgements}

\section{Conflict of interest statement}

The authors declare no conflict of interest.

\section{Funding sources}

There are no sources of funding to declare.

\section{References}

1. Daly AF, Rixhon M, Adam C, Dempegioti A, Tichomirowa MA, Beckers A. High Prevalence of Pituitary Adenomas: A Cross-Sectional Study in the Province of Liège, Belgium. The Journal of Clinical Endocrinology \& Metabolism. 2006 Dec 1;91(12):4769-4775. https://doi.org/10.1210/jc. 2006-1668

2. Fernandez A, Karavitaki N, Wass JAH. Prevalence of pituitary adenomas: a community-based, crosssectional study in Banbury (Oxfordshire, UK). Clinical Endocrinology. 2010 Mar;72(3):377-382. https://doi. org/10.1111/j.1365-2265.2009.03667.x

3. Colao A, Ferone D, Marzullo P, Lombardi G. Systemic Complications of Acromegaly: Epidemiology, Pathogenesis, and Management. Endocrine Reviews. 2004 Feb 1;25(1):102-152. https://doi.org/10.1210/er.20020022

4. Melmed S. Acromegaly. New England Journal of Medicine. 2006 Dec 14;355(24):2558-2573. https:// doi.org/10.1056/nejmra062453

5. Bolanowski M, Ruchała M, Zgliczyński W, Kos-Kudła B, Hubalewska-Dydejczyk A, Lewiński A. Diagnostics and treatment of acromegaly - updated recommendations of the Polish Society of Endocrinology. Endokrynol Pol.. 2019;70(1):2-18. https://doi. org/10.5603/EP.a2018.0093

6. Celik $O$, Kadioglu P. Quality of life in female patients with acromegaly. Journal of Endocrinological Investigation. 2013 Jun;36(6). https://doi.org/10.3275/8761

7. Celik O, Hatipoglu E, Akhan SE, Uludag S, Kadioglu P. Acromegaly is associated with higher frequency of female sexual dysfunction: experience of a single center. Endocrine Journal. 2013;60(6):753-761. https://doi.org/10.1507/endocrj.ej12-0424

8. T'Sjoen G, Bex M, Maiter D, Velkeniers B, Abs R. Health-related quality of life in acromegalic subjects: data from AcroBel, the Belgian Registry on acromegaly. European Journal of Endocrinology. 2007 Oct;157(4):411-417. https://doi.org/10.1530/eje-070356

9. Webb SM. Quality of Life in Acromegaly. Neuroendocrinology. 2006;83(3-4):224-229. https://doi. org/10.1159/000095532

10. Webb SM, Badia X. Quality of Life in Growth Hormone Deficiency and Acromegaly. Endocrinology and Metabolism Clinics of North America. 2007 Mar;36(1):221-232. https://doi.org/10.1016/j. ecl.2006.11.011

11. Åberg ND, Brywe KG, Isgaard J. Aspects of Growth Hormone and Insulin-Like Growth Factor-I Related to Neuroprotection, Regeneration, and Functional Plasticity in the Adult Brain. The Scientific World JOURNAL. 2006;6:53-80. https://doi.org/10.1100/ tsw. 2006.22

12. Martín-Rodríguez JF, Madrazo-Atutxa A, VenegasMoreno E, Benito-López P, Gálvez MÁ, Cano DA, Tinahones FJ, Torres-Vela E, Soto-Moreno A, LealCerro A. Neurocognitive Function in Acromegaly 
after Surgical Resection of GH-Secreting Adenoma versus Naïve Acromegaly. Wolfe A. PLoS ONE. 2013 Apr 4;8(4):e60041. https://doi.org/10.1371/journal. pone. 0060041

13. Smarr KL, Keefer AL. Measures of depression and depressive symptoms: Beck Depression InventoryII (BDI-II), Center for Epidemiologic Studies Depression Scale (CES-D), Geriatric Depression Scale (GDS), Hospital Anxiety and Depression Scale (HADS), and Patient Health Questionna. Arthritis Care \& Research. 2011 Nov;63(S11):S454-S466. https://doi. org/10.1002/acr.20556

14. Wciórka J, Pużyński S. Narzędzia oceny stanu psychicznego. In: Rybakowski J, Pużyński S, Wciórka J, eds. Psychiatria. Podstawy psychiatrii. 1. Wrocław: Elsevier Urban \& Partner; 2010:455-6.

15. Zawadzki B, Popiel A, Pragłowska E. Charakterystyka psychometryczna polskiej adaptacji Kwestionariusza Depresji BDI-II Aarona T. Becka. Psychol Etol Genet. 2009;19:71-95

16. Oleszko A, Szczepańska E, Janion K, Jośko-Ochojska J. Nutrition behaviours and the occurrence of depressive symptoms among the students in the institutions of higher education in Silesia (Poland). Roczniki Państwowego Zakładu Higieny. 2019;:69-77. https://doi.org/10.32394/rpzh.2019.0056

17. Bleuler M. The psychopathology of acromegaly. J Nerv Ment Diseases.1951(113):497-511.

18. Michael R, Gibbons J. Inter-relationships between the endocrine system and neuropsychiatry. Int Rev Neurobiol. 1963;5:243-302. https://doi.org/10.1016/ s0074-7742(08)60597-8

19. Beumont P. Endocrines and psychiatry. Br J Hosp Med. 1972;7:485-97.

20. Avery TL. A Case of Acromegaly and Gigantism with Depression. British Journal of Psychiatry. 1973 May;122(570):599-600. https://doi.org/10.1192/ bjp.122.5.599

21. Labhart A. Clinical Endocrinology. 1. Berlin-Heidelberg: Springer-Verlag Berlin-Heidelberg; 1974. https://doi.org/10.1007/978-3-642-96158-8

22. Margo A. Acromegaly and Depression. British Journal of Psychiatry. 1981 Nov;139(5):467-468. https:// doi.org/10.1192/bjp.139.5.467

23. Lishman W. Organic psychiatry, the psychological consequences of cerebral disorders. 2. London: Blackwell Scientific Publications; 1987.

24. Kuśmierek M, Florkowski A, Gałecki P, Talarowska M. Comorbidity of psychiatric and somatic disorders among patients diagnosed with depression. Curr Probl Psych. 2011;12(3):285-92.

25. Ryszard Piotrowicz, Joanna Potocka, Aleksander Araszkiewicz, Marcin Wojnar, Dorota NawackaPawlaczyk. Depresja jako problem kardiologiczny w praktyce lekarzy podstawowej opieki zdrowotnej. Folia Cardiologica Excerpta. 2003;10(2):177-84.

26. Hajduk A, Korzonek M, Przybycień K, Ertmański S, Stolarek J. Badanie depresyjności skala depresji Becka u pacjentów z zaburzeniami rytmu serca [Study of depressiveness with Beck Depression Inventory in patients with cardiac arrhythmias]. Ann Acad Med Stetin. 2011;57(1):45-8. PMID 22593990
27. Bokma WA, Batelaan NM, van Balkom AJ, Penninx BW. Impact of Anxiety and/or Depressive Disorders and Chronic Somatic Diseases on disability and work impairment. Journal of Psychosomatic Research. 2017 Mar;94:10-16. https://doi.org/10.1016/j. jpsychores.2017.01.004

28. Szpakowski N, Bennell MC, Qiu F, Ko DT, Tu JV, Kurdyak P, Wijeysundera HC. Clinical Impact of Subsequent Depression in Patients With a New Diagnosis of Stable Angina. Circulation: Cardiovascular Quality and Outcomes. 2016 Nov;9(6):731-739. https://doi. org/10.1161/circoutcomes.116.002904

29. Dudek D, Sobański JA. Mental disorders in somatic diseases: psychopathology and treatment. Polish Archives of Internal Medicine. 2012 Nov 18;122(12):624629. https://doi.org/10.20452/pamw.1539

30. Dudek D, Siwek M. Depression in medical illness. Psychiatria. 2007;4(1):17-24.

31. Whisman MA, Perez JE, Ramel W. Factor structure of the Beck Depression Inventory-Second Edition (BDI-ii) in a student sample. Journal of Clinical Psychology. 2000 Apr;56(4):545-551. https://doi. org/10.1002/(sici)1097-4679(200004)56:4<545::aidjclp7>3.0.co;2-u

32. Lopuszańska M, Szklarska A, Jankowska E. Ocena nasilenia objawów depresyjnych z zastosowaniem polskiej wersji IA Inwentarza Depresji Becka u zdrowych mezczyzn, mieszkańców Wrocławia [Assessment of severity of depressive symptoms using the Polish version IA of Beck Depression Inventory in healthy men, inhabitants of Wrocław]. Psychiatr Pol. 2013 Nov-Dec;47(6):1001-9. PMID 25007533

33. Crespo I, Santos A, Valassi E, Pires P, Webb SM, Resmini E. Impaired decision making and delayed memory are related with anxiety and depressive symptoms in acromegaly. Endocrine. 2015 May 28;50(3):756-763. https://doi.org/10.1007/s12020015-0634-6

34. Pantanetti P, Sonino N, Arnaldi G, Boscaro M. Self image and quality of life in acromegaly. Pituitary. 2002;5:17-9. https://doi.org/10.1023/ a:1022145116901

35. Furman K, Ezzat S. Psychological Features of Acromegaly. Psychotherapy and Psychosomatics. 1998;67(3):147-153. https://doi. org/10.1159/000012275

36. Biermasz NR, Pereira AM, Smit JWA, Romijn JA, RoeIfsema F. Morbidity after Long-Term Remission for Acromegaly: Persisting Joint-Related Complaints Cause Reduced Quality of Life. The Journal of Clinical Endocrinology \& Metabolism. 2005 May;90(5):27312739. https://doi.org/10.1210/jc. 2004-2297

37. Geraedts VJ, Dimopoulou C, Auer M, Schopohl J, Stalla GK, Sievers C. Health Outcomes in Acromegaly: Depression and Anxiety are Promising Targets for Improving Reduced Quality of Life. Frontiers in Endocrinology. 2015 Jan 6;5. https://doi.org/10.3389/ fendo.2014.00229

38. De Sousa A. Depression in Acromegaly Treated with Escitalopram and Cognitive Therapy. Indian Journal of Psychological Medicine. 2009 Jan;31(1):50-51. https://doi.org/10.4103/0253-7176.53317 